\title{
Pyrolysis-field ionization mass spectrometry of rhizodeposits - a new approach to identify potential effects of genetically modified plants on soil organisms
}

\author{
Alexei MELNITCHOUCK ${ }^{1}$, Peter LEINWEBER ${ }^{2 *}$, Inge BROER ${ }^{2}$ and Kai-Uwe ECKHARDT ${ }^{2}$ \\ ${ }^{1}$ Environmental Solutions ${ }^{\mathrm{TM}}$ Remediation Services, 807 Manning Road N.E., Suite \#100, Calgary, AB T2E 7M8, Canada \\ ${ }^{2}$ Institute for Land Use, University of Rostock, Justus-von-Liebig-Weg 6, 18059 Rostock, Germany
}

\begin{abstract}
The objectives of the present study were (1) to investigate the qualitative composition of rhizodeposits leached from soils cropped with non-transgenic and genetically modified (GM) potatoes, and disclose if there were GMspecific modifications in potato rhizodeposition, and (2) to compare these results with conventional bulk parameters of microbial activity in soil. We have raised potatoes from a non-transgenic line (Solanum tuberosum L. cv. Désirée) and three GM lines, which expressed a gene for the resistance to kanamycin (DLH 9000) and a gene for T4 lysozyme (DL10 and DL12). A sandy soil placed in $340 \mathrm{~cm}^{3}$-"CombiSart" containers was used, from which the rhizodeposit was leached after a six-week growth period. The freeze-dried leachates were analyzed by pyrolysis-field ionization mass spectrometry (Py-FIMS). The Py-FI mass spectra gave detailed molecular-chemical information about the composition of leachates, indicating that the potato growth generally altered the composition of the soil solution. Moreover, a principal component analysis of the mass spectra showed differences between the leachates from the non-transgenic parent line and the GM potatoes as well as among the latter group. However, these differences in molecular composition could not be assigned to the release of T4-lysozyme into soil. Dehydrogenase activity and substrate-induced soil respiration as more common bulk parameters of soil microbial activity failed to disclose any significant effects of the various potatoes grown. The limitations of the described rhizodeposit leaching and analysis for risk assessment of GM potato cropping under field conditions are discussed critically. However, it could be concluded that the Py-FI mass spectrometric "fingerprint" can be developed as a fast, comprehensive, highly sensitive and reproducible analytical approach to discern any effects GM-crops may exert on soil ecological parameters.
\end{abstract}

Keywords: biosafety / risk assessment / genetically modified plants / potato / rhizodeposition / pyrolysis / T4 lysozyme

\section{INTRODUCTION}

Soil is the first component of the environment that could be affected by genetically modified (GM) crops. Generally, there are two pathways for plant organic matter influences on soil, (1) rhizodeposition, i.e. the root exudation and deposition of all other root-derived organic substances in the rhizosphere, and (2) incorporation of non-harvested plant residues such as leaves, stems and roots into the tilled soil layer (Brady, 1990). Irrespective of the pathway, this organic matter is potentially consumed by soil organisms. Therefore, a modified composition of plant biomass can affect the consumer populations of which microorganisms form the largest group by number, weight and importance for biochemical soil processes (Paul and Clark, 1996). Furthermore, genetic modification to increase crop resistance to soilborne pathogens can also affect other microorganisms important for crop development (de Vries et al., 1999). For example, Cowgill et al. (2002) reported changes in the community structure of rhizosphere microbes caused by transgenic potatoes expressing the genes for chicken egg white cystatin $(\mathrm{CEWc})$ or a modified version of rice cystatin (Oc-I $\Delta \mathrm{D} 86)$. On the other hand, bacterial communities in the crop rhizosphere are sensitive to different environmental factors, like weather conditions,

\footnotetext{
* Corresponding author: peter.leinweber@uni-rostock.de
} 
A. Melnitchouck et al.

Table 1. Concentrations of carbon $(\mathrm{C})$, nitrogen $(\mathrm{N})$ and sulfur $(\mathrm{S})$ in the leachates from the non-cropped sandy soil (Control) and in the rhizodeposits from the sandy soil planted with non-transgenic (WT) and transgenic potatoes (LH9000, DL10 and DL12) (means \pm standard deviations of three replicates, $\mathrm{g} . \mathrm{kg}^{-1}$ dry matter).

\begin{tabular}{lccccc}
\hline \hline Elements & Control & WT & LH9000 & DL10 & DL12 \\
\hline $\mathrm{C}$ & $15.5 \pm 3.7$ & $90.2 \pm 16.0$ & $94.9 \pm 4.1$ & $96.8 \pm 21.4$ & $93.3 \pm 14.4$ \\
$\mathrm{~N}$ & $26.6 \pm 10.5$ & $20.2 \pm 7.2$ & $21.8 \pm 9.0$ & $17.2 \pm 4.8$ & $18.2 \pm 6.5$ \\
$\mathrm{~S}$ & $6.2 \pm 2.0$ & $32.4 \pm 7.5$ & $35.6 \pm 12.7$ & $36.8 \pm 11.7$ & $42.9 \pm 5.9$ \\
$\mathrm{C}: \mathrm{N}$ ratio & 0.6 & 4.5 & 4.4 & 5.6 & 5.1 \\
C:S ratio & 2.5 & 2.8 & 2.7 & 2.6 & 2.0 \\
\hline
\end{tabular}

seasonal changes in soil moisture and temperature, soil $\mathrm{pH}$ etc. (Wood, 1995). A detailed analysis carried out by Heuer et al. (2002) showed that effects the of T4 lysozyme released from transgenic potato roots on bacterial rhizosphere communities were negligible relative to natural factors, though as a pure substance, T4 lysozyme affects both gram-positive and gram-negative bacteria.

In a recent comprehensive review, Bruinsma et al. (2003) summarized the case-by-case studies of the influence of GM crops on soil microorganisms. They proposed a two-pronged approach to study potential effects of GM crops: (1) to investigate specific microbial groups and processes, and (2) to implement general analyses that may detect effects outside the scope of predicted microbial groups and processes. Substrateinduced respiration, enzyme activities (Sessitsch et al., 2004), and the quantitative and qualitative analysis of rhizodeposition are such general integrative parameters, which can indicate significant or insignificant effects of growing GM crops on microbial communities in the rhizosphere, as concluded, e.g., by Brusetti et al. (2004).

Recently, pyrolysis-field ionization mass spectrometry (Py-FIMS) was shown to be a rapid and highly sensitive method for the analysis of leached maize rhizodeposits (Kuzyakov et al., 2003), which enabled detection of differences in the composition of maize rhizodeposits between day- and nighttime (Melnitchouck et al., 2005). Rhizodeposits of potato plants have not been investigated by modern analytical methods and, accordingly, rhizodeposits of transgenic plants have not been compared to those of non-transgenic ones. Therefore, the objectives of the present study were (1) to investigate the qualitative composition of rhizodeposits leached from non-cropped soil and the same soil grown with non-transgenic and T4lysozyme potatoes by Py-FIMS, and determine if there were lysozyme-specific modifications in potato rhizodeposition; (2) to investigate the decomposition of crop residues by means of soil respiration and dehydro- genase activity, as two additional general indicators of possible effects of T4-lysozyme potatoes on soil microorganisms. The general purpose of this research is to develop rapid and low cost test systems to find out whether GM crops exert transgene-specific effects on the soil rhizosphere, or not.

\section{RESULTS AND DISCUSSION}

\section{Elemental analysis of the rhizodeposits}

Table 1 shows that leachates from the soils with the plants had larger $\mathrm{C}$ and $\mathrm{S}$, and smaller $\mathrm{N}$ concentrations than the leachate from the non-cropped soil. Although the $\mathrm{C}, \mathrm{N}$, and $\mathrm{S}$ concentrations varied between the replicated samples, one-way ANOVA showed that these differences were significant. The $\mathrm{C}: \mathrm{N}$ ratio was extremely narrow in the leachate from the unplanted soil (about 0.6:1), indicating the leaching of mineral $\mathrm{N}\left(\mathrm{NH}_{4}{ }^{+}, \mathrm{NO}_{3}{ }^{-}\right)$. The $\mathrm{C}: \mathrm{N}$ ratio in the leachates from the soils cropped with potatoes was wider, but still narrow. The mean $\mathrm{C}: \mathrm{N}$ ratio of $5: 1$ of rhizodeposits was lower than the average value for the whole soil $(9.9: 1)$. This indicates that potato rhizodeposits were richer in $\mathrm{N}$ than the whole soil.

The $\mathrm{C}$ and $\mathrm{N}$ concentrations in potato rhizodeposits were lower than the values obtained for maize in our previous research, whereas the concentration of $\mathrm{S}$ was higher (Melnitchouck et al., 2005). Since we used the same soil for the two experiments, this difference indicates that the composition of the rhizodeposits may be crop specific. There were no differences significant at $P \leq 0.05$ between elemental concentrations and ratios of rhizodeposits from non-transgenic and transgenic potatoes. The similarity of all samples from the cropped soil indicated no significant effect of T4-lysozyme potatoes on the elemental composition of rhizodeposits. 


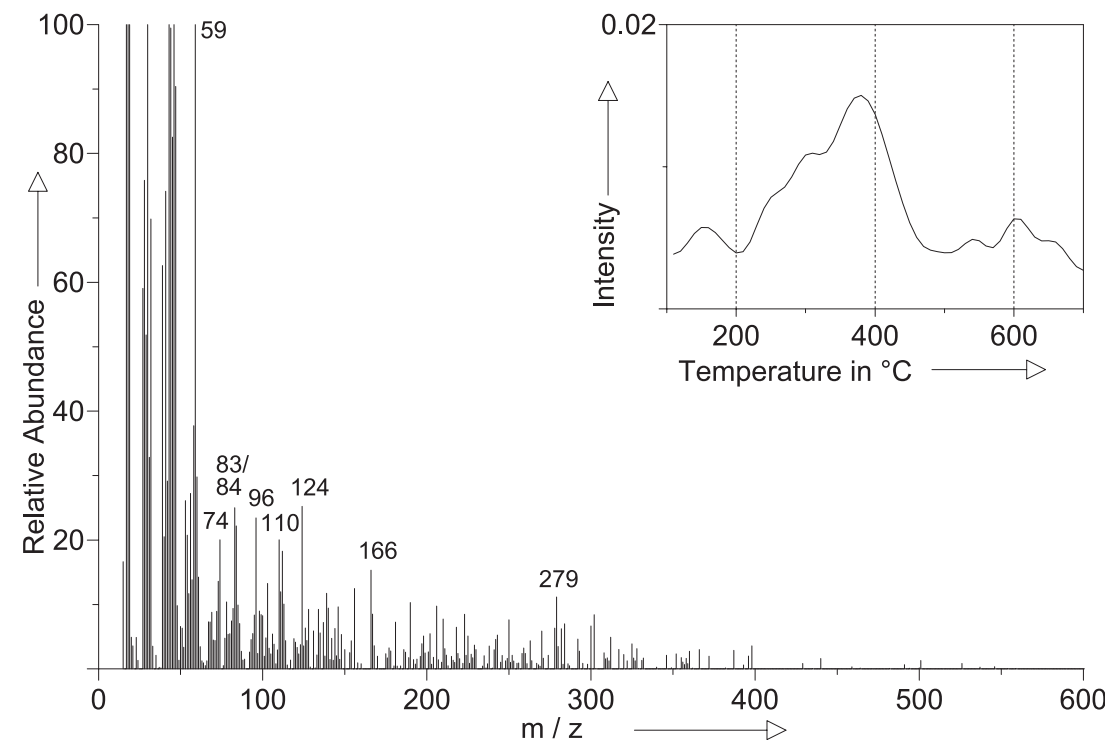

Figure 1. Thermogram of total ion intensity (upper right) and summed and averaged pyrolysis-field ionization mass spectra of a leachate from the sandy soil used for the potato growth experiment.

\section{Pyrolysis-field ionization mass spectrometry}

The Py-FI mass spectrum of the leachate from the noncropped soil was characterized by a low total ion intensity of $0.414 \times 10^{6}$ counts. $\mathrm{mg}^{-1}$ (not shown), large proportions of unspecific signals in the low-mass range $(\mathrm{m} / \mathrm{z}<56)$, an intense signal of acetamide $(\mathrm{m} / \mathrm{z}, 59)$ indicating the pyrolysis of $\mathrm{N}$-containing compounds, and a relatively low abundance of marker signals for carbohydrates $(\mathrm{m} / \mathrm{z}$ 84, 96 and 110), phenols and lignin monomers $(\mathrm{m} / \mathrm{z} 124$, 166, 208), alkylaromatics $(\mathrm{m} / \mathrm{z}, 190,302)$ and $\mathrm{N}-$ containing compounds $(\mathrm{m} / \mathrm{z} 279$, nonadecanenitrile) (Fig. 1). The thermogram of total ion intensity (upper right) indicated a maximum of volatilization at $380{ }^{\circ} \mathrm{C}$, which is typical for dissolved organic matter (Schulten et al., 2002).

The Py-FI mass spectra of leachates from the soils with potato plants were more intense by an average factor of 4.5 and covered a wider range of $\mathrm{m} / \mathrm{z}$ (up to $>500$ ) (Fig. 2 a-d) compared to the spectrum in Figure 1. These spectra had more than 200 additional signals in the range from $\mathrm{m} / \mathrm{z} 15$ to 500 , which were not present in the leachate from the non-cropped soil. Most intense in the lower mass range were signals assigned to peptides $(\mathrm{m} / \mathrm{z} 45,57,70,74,84$ and $97,146,147)$, heterocyclic $\mathrm{N}$ containing compounds $(\mathrm{m} / \mathrm{z}, 59,67,79,81,95,103,109)$ and carbohydrates $(\mathrm{m} / \mathrm{z}$ $84,96,110$ and 126). In the medium and higher mass range, signals of phenols and lignin monomers $(\mathrm{m} / \mathrm{z} 152$, 178, 180, 194, 196, 208, 210), alkylaromatics $(\mathrm{m} / \mathrm{z}, 192$,
$220)$, unsaturated fatty acids $(\mathrm{m} / \mathrm{z} 240,266,280)$, lipids and saturated fatty acids $(\mathrm{m} / \mathrm{z}, 256,298)$ were most abundant. Sterols were indicated by $\mathrm{m} / \mathrm{z} 394,396,402,408$ and 426 .

The visual comparison of Figures 1 and 2 clearly shows that growth of potatoes substantially influenced the chemical composition of leachates, irrespective of nontransgenic or transgenic lines. The by far more intensive Py-FI mass spectra (see scale of TII-thermograms), showing a wider molecular diversity and mass range of the signals recorded in Figure 2 compared to Figure 1, are explained by the potato rhizopedosits cumulated over the six-week growth period, their microbial decomposition products, and leachable products of interaction with the genuine soil organic matter (Kuzyakov et al., 2003; Melnitchouck et al., 2005). The Py-FI mass spectra in Figure 2 also indicate visual differences in the molecular composition of leachates among the four variants with potatoes grown. Considering the molecular composition of T4 lysozyme, it has to be determined if these differences originate from T4 lysozyme deposited in soil. A molecule of T4 lysozyme consists of 164 amino acids, and about $80 \%$ of them are alanine, arginine, asparagine, aspartic acid, glycine, glutamic acid, isoleucine, leucine, lysine, threonine and valine (Protein Data Bank, 2003). The expression of T4 lysozyme was determined to be relatively constant and did not exceed $0.0014 \%$ of total plant protein (Düring and Mahn, 1999). Data about the specific proportions of this enzyme in plant rhizodeposits were not available. However, if T4 lysozyme was stable 
a)

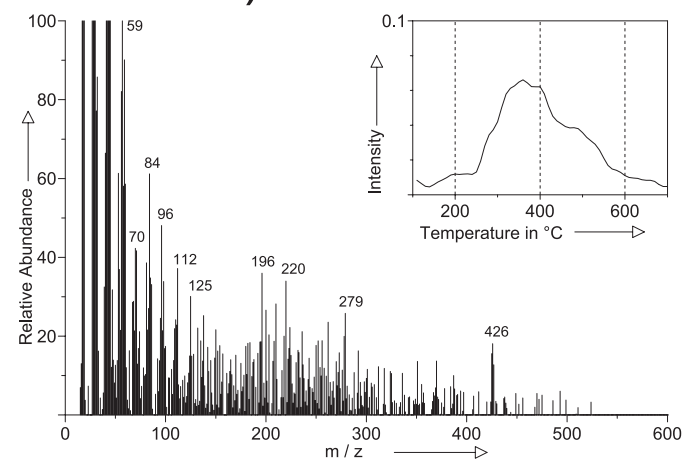

c)

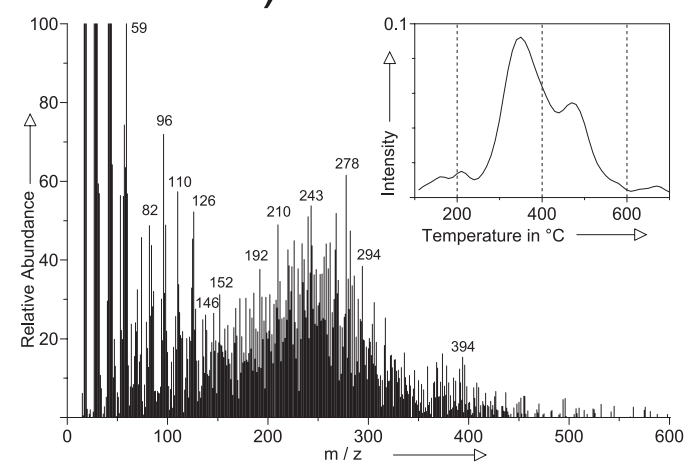

b)

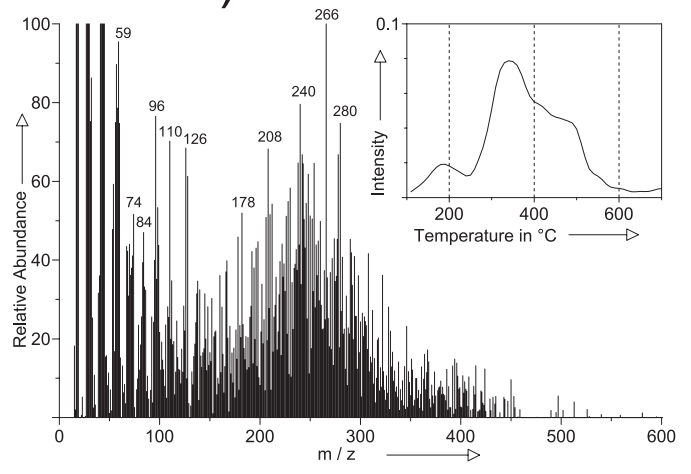

d)

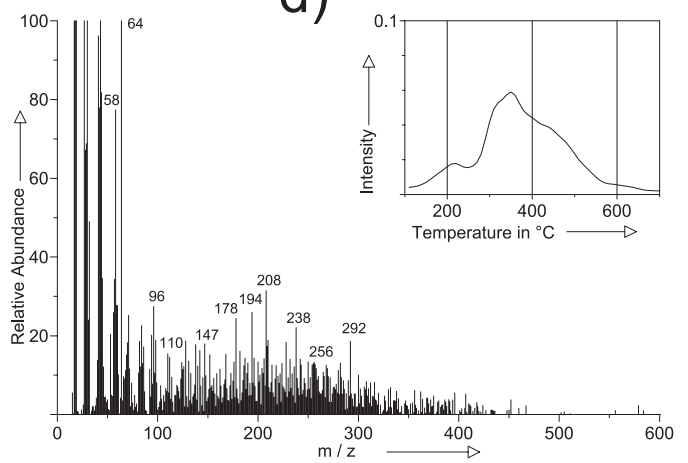

Figure 2. Thermograms of total ion intensity (upper right) and summed and averaged pyrolysis-field ionization mass spectra of leachates from non-transgenic and GM potatoes grown for 6 weeks in a sandy soil. (a) cv. Désirée, non-transgenic potato (WT); (b) transgenic line expressing a gene for the resistance to kanamycin (LH9000); (c) transgenic line expressing a gene for T4 lysozyme (DL10); and (d) transgenic line expressing a gene for T4 lysozyme (DL12).

in soils, the amino acids constituting its molecules should be detected in the samples DL10 and DL12.

In Py-FIMS mass spectra, $m / z, 57$ is a typical pyrolysis product of threonine, leucine and isoleucine (Sorge et al., 1993), and $\mathrm{m} / \mathrm{z} 45$ can be formed from all peptides. As these signals were intense in all leachates, including those from non-cropped soil, we assume that T4 lysozyme was definitely not the main source of these signals. The intense signal $\mathrm{m} / \mathrm{z} 84$ can originate from carbohydrates and glutamic acid or glutamine. The marker peaks for glutamine, glutamic acid and lysine are $m / z$ 130, 146, 147 (Sorge et al., 1993). Although there were some differences in the abundances of these three signals, no particular enrichment in the spectra from samples DL10 and DL12 was visible. The relative abundances of $\mathrm{m} / \mathrm{z}, 97$ (aspartic acid) and $m / z 99$ (fragment of asparagine) were similar in all the samples obtained from the soils with nontransgenic plants. $M / z 115$ and 133, which are the base peaks for arginine and asparagine, were weak in all the samples. According to Hütsch et al. (2002), glutamine, aspartic acid and serine represent $72.9 \%$ of amino acids exuded by maize roots. In our case, the most intense signals assigned to peptides arose from glutamine, leucine, isoleucine and threonine. This difference indicates that the plant species may determine the amino acid composition in rhizodeposits. However, the detailed inspection of the characteristic signals from amino acids occurring in T4-lysozyme did not indicate an influence of the expression of this protein in the transgenic lines on the composition of the leachates.

Several signals detected in the samples with the plants but absent in the non-cropped soil originated from sterols, 
Pyrolysis-field ionization mass spectrometry of rhizodeposits

Table 2. Main classes of organic compounds as derived from the pyrolysis-field ionization mass spectra; in $\%$ total ion intensity (TII) \pm standard deviation: carbohydrates $=$ CHYDR, phenols + lignin monomers = PHLM, lignin dimers = LDIM, lipids = LIPID, alkyl aromatics $=$ ALKY, heterocyclic nitrogen containing compounds $=$ NCOMP, sterols $=$ STEROL, peptides $=$ PEPTI, suberin $=$ SUBER, free fatty acids $=$ FATTY .

\begin{tabular}{lccccccccccccc}
\hline \hline Samples & Units & CHYDR* & PHLM* & LDIM & LIPID & ALKY* & NCOMP & STEROL PEPTI** & SUBER FATTY* & m/z 15-56* & Total \\
\hline Control & \% TII & $2.0 \pm 0.4$ & $1.1 \pm 0.3$ & $0.3 \pm 0.3$ & $0.4 \pm 0.1$ & $1.1 \pm 0.7$ & $3.4 \pm 1.4$ & $0.03 \pm 0.0$ & $1.3 \pm 0.5$ & $0.0 \pm 0.0$ & $0.1 \pm 0.0$ & $84.0 \pm 4.7$ & 100.0 \\
WT & & $4.0 \pm 0.8$ & $5.1 \pm 1.6$ & $1.5 \pm 1.4$ & $3.6 \pm 1.8$ & $5.4 \pm 2.5$ & $5.7 \pm 1.4$ & $0.5 \pm 0.3$ & $3.3 \pm 0.3$ & $0.0 \pm 0.0$ & $1.1 \pm 0.5$ & $42.5 \pm 21.8$ & 100.0 \\
DL10 & $4.9 \pm 1.0$ & $5.9 \pm 0.8$ & $1.3 \pm 0.9$ & $5.6 \pm 1.9$ & $6.4 \pm 1.2$ & $6.1 \pm 1.3$ & $1.0 \pm 0.6$ & $3.7 \pm 0.1$ & $0.0 \pm 0.0$ & $1.9 \pm 0.4$ & $31.5 \pm 13.2$ & 100.0 \\
DL12 & $4.2 \pm 1.1$ & $6.1 \pm 2.2$ & $1.8 \pm 0.7$ & $3.3 \pm 1.2$ & $5.5 \pm 0.9$ & $4.3 \pm 0.9$ & $0.7 \pm 0.2$ & $2.9 \pm 0.2$ & $0.1 \pm 0.2$ & $1.1 \pm 0.6$ & $44.7 \pm 7.0$ & 100.0 \\
LH9000 & $4.3 \pm 0.7$ & $5.6 \pm 2.5$ & $2.1 \pm 1.8$ & $4.9 \pm 2.6$ & $6.2 \pm 2.3$ & $5.0 \pm 1.4$ & $0.8 \pm 0.7$ & $3.1 \pm 0.5$ & $0.1 \pm 0.05$ & $1.6 \pm 0.9$ & $39.0 \pm 22.5$ & 100.0
\end{tabular}

* The difference between the samples from planted and unplanted soils is significant at $P \leq 0.05$.

** The difference between the samples is significant at $P \leq 0.01$.

in particular $m / z 394$ and 396 (see Fig. 2 and compare with Fig. 1). $M / z 396$ relates to ergosterol, which is a fungalspecific membrane lipid, in particular, for Glomus sp. (Kjøller and Rosendahl, 2000). As potato can develop endomycorrhiza with these fungal strains (Rausch et al., 2001), presence of this compound in the samples is interpreted as indication that endomycorrhizal fungi were not affected by T4 lysozyme.

Table 2 shows the summed ion intensities for each of 10 classes of organic compounds derived from the Py-FI mass spectra. Leachates from the non-cropped soil had about $78 \%$ of low-mass and non-specific signals. Rhizodeposits from all the soils with potato plants had higher proportions of all the main compound classes, especially carbohydrates, phenols and lignin monomers, lipids, fatty acids and peptides. This indicates that rhizodeposits were not immediately decomposed, and remained in soil, at least to a certain extent, over the sixweek growing period. ANOVA of these data showed that the differences between the samples from non-cropped soil and soils with potato plants were significant at $P<0.05$ for carbohydrates, phenols and lignin monomers, free fatty acids, alkylaromatics and peptides, regardless of the plant genotype. There was no significant difference between the rhizodeposits of non-transgenic and T4-lysozyme potatoes.

In order to show the sensitivity of Py-FIMS and find out which $\mathrm{m} / \mathrm{z}$ determined the differences between rhizodeposits in the potato varieties, we carried out a principal component analysis (PCA). The signals with the largest variance weights for the discrimination between the four sample groups were $m / z, 189,131,202,214,226$, $71,84,208,125,164$ and 280. These indicate Ncontaining compounds (e.g. methylindole: $\mathrm{m} / \mathrm{z}$ 131, pyrolysis products of glutamine and glutamic acid: $\mathrm{m} / \mathrm{z} 84$;

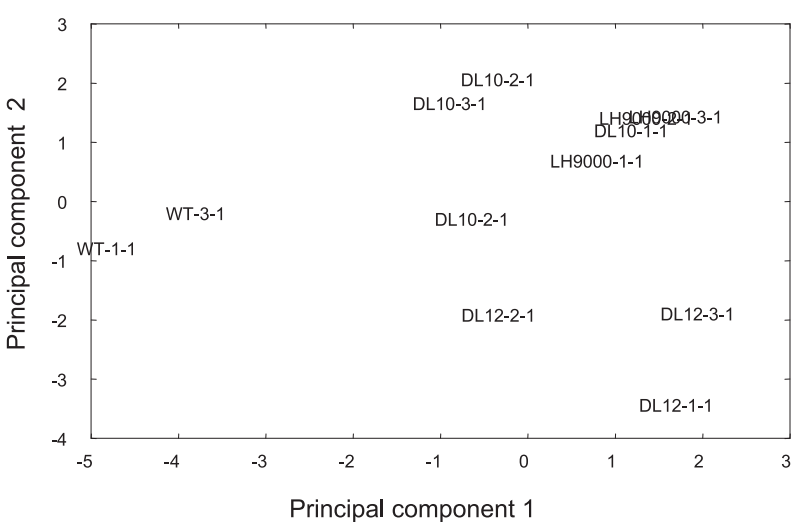

Figure 3. Plot of the principal components 1 and 2 calculated from pyrolysis-field ionization mass spectra of soil leachates, collected after six-week growth of non-transgenic (WT) and GM potatoes (LH 9000, DL10 and DL12; for explanation of abbreviations see Fig. 2).

substituted pyrrole or pyridine: $\mathrm{m} / \mathrm{z}, 125)$ and lignin building blocks. The plot of principal component (PC) 2 versus $\mathrm{PC} 1$ unequivocally shows that there were differences between the leachates from the same line and between leachates from the different lines (Fig. 3). Furthermore, PC1 discriminated between the wild-type potato and all transgenic lines. The two signals with the highest negative loadings, $\mathrm{m} / \mathrm{z} 189$ and $\mathrm{m} / \mathrm{z} 131$ (indole derivate from pyrolysis of glutamine and/or glutamic acid) were more abundant in the leachates from the wild-type than in the leachates from the GM plants.

The clear discrimination of the various potato lines based on PCA of Py-FI mass spectra of leachates in the first instance confirms that Py-FIMS is extremely 


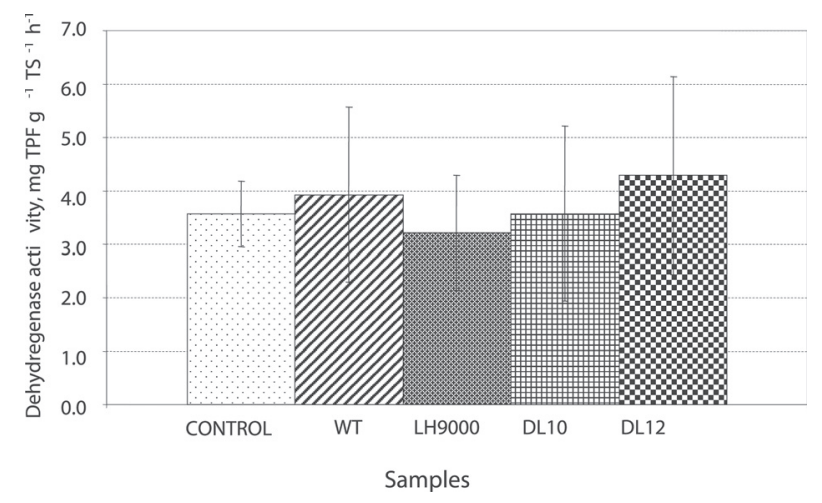

Figure 4. Dehydrogenase activity in soils grown with nontransgenic (WT) and GM potatoes (LH 9000, DL10 and DL12; for explanation of abbreviations see Fig. 2).

sensitive to differences in the molecular-chemical composition of complex heterogeneous biomaterials. This was also concluded from investigations of fulvic acids in fen soils (Leinweber et al., 2001), and more recently, of rhizodeposits leached from non-transgenic crops (Kuzyakov et al., 2003; Melnitchouck et al., 2005). Thus, either a higher sensitivity of Py-FIMS, or principal differences between potato and pea, can explain the disagreement to Gransee and Wittenmeyer (2000), who did not find significant differences in carbohydrates, amino acids and carboxylic acids between the exudates of two non-transgenic pea cultivars with common chromatographic techniques.

\section{Dehydrogenase activity and soil respiration}

Figure 4 shows that the dehydrogenase activities varied between 3 and $7 \mu \mathrm{g}$ TPF. $\mathrm{g}^{-1}$. TS ${ }^{-1} \cdot \mathrm{h}^{-1}$. The dehydrogenase activities were not affected by growing the potato plants. Furthermore, there was no significant difference between soils grown with wild-type and transgenic potatoes. Generally, the dehydrogenase activities were in the same order of magnitude as determined for a range of sandy loams under crop rotations (Simek et al., 1999). Though this characteristic is not consistently correlated to the number of microorganisms, $\mathrm{CO}_{2}$ evolution or $\mathrm{O}_{2}$ consumption, dehydrogenase reflects a broad range of microbial oxidative activities (Tabatabai, 1994). It can be influenced not only by enzyme concentration, but also by the nature and concentration of added and endogenous $\mathrm{C}$ substrates and alternate electron acceptors (Verhoef and van Gestel, 1995). In the present investigation, the only sources of $\mathrm{C}$ amendment were the potato rhizodeposits and the products of microbial activity. Therefore, potato growing did not have a measurable effect on a wide range of soil bacteria.

Figure 5 shows that the curves of $\mathrm{CO}_{2}$ emission were similar in all the variants of the experiment. The lowest values were obtained for the non-cropped soil. The soils after the growing of the lines DL10 and DL12 had slightly increased rates of $\mathrm{CO}_{2}$ emission, however, the difference between all the variants determined by t-test was insignificant at $P \leq 0.05$, except for the non-cropped soil. Soil respiration is an integral characteristic describing the activity of soil microflora, and the rates of respiration can

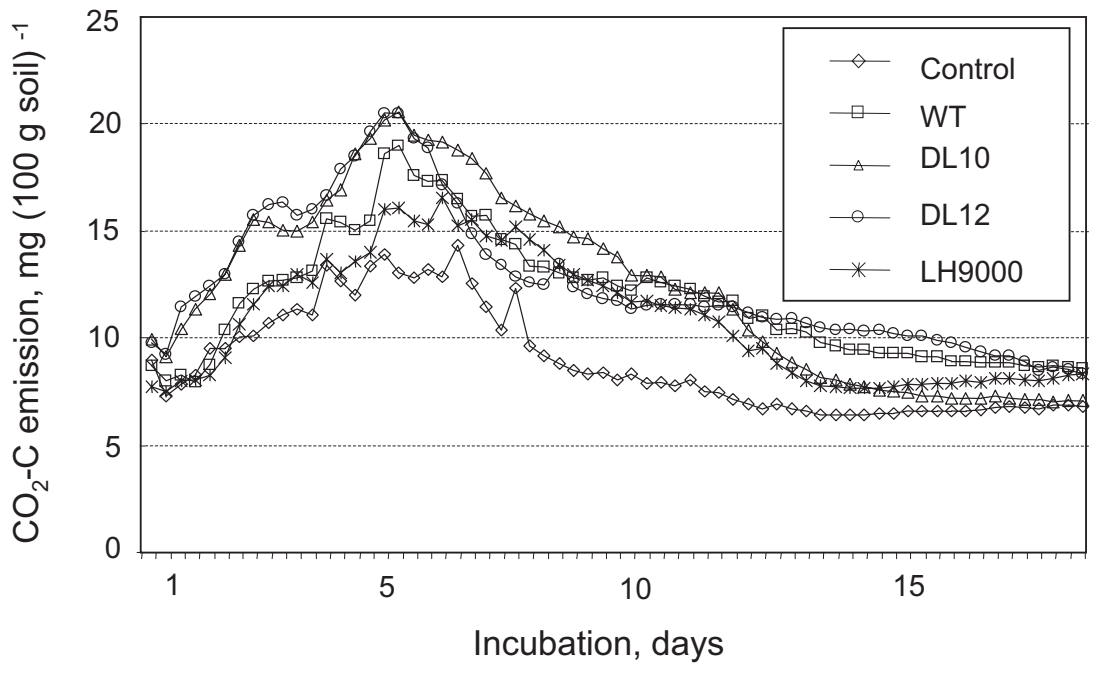

Figure 5. Substrate-induced respiration: $\mathrm{CO}_{2}$ emission from the soils after growth of non-transgenic (WT) and GM potatoes (LH 9000, DL10 and DL12; for explanation of abbreviations see Fig. 2). 
be used to assess the overall effect of root exudates on soil microorganisms. The similarity in all respiration curves from soils with potato plants confirms the explanation of dehydrogenase activities.

A comparison of the three methodological approaches to determine effects of non-transgenic and transgenic potatoes on soil molecular and microbial properties results in a clear sequence of sensitivity: Py-FIMS of rhizodeposits $>$ dehydrogenase activity $>$ substrate-induced respiration. However, even the most sensitive method failed to disclose modifications in rhizodeposition that could be assigned directly to the expression and release of T4-lysozyme. In more localized measurements directly at the rhizoplane, it has been demonstrated that T4 lysozyme release from root hairs increased the killing of rootadsorbed Bacillus subtilis cells (Ahrenholz et al., 2000). Differences in the abundance and diversity of plant-beneficial bacteria were detected in the rhizosphere of T4 lysozyme and control potato plants, but there was no clear correlation with T4 lysozyme release from the roots (Lottmann et al., 1999). Most probably, T4 lysozyme released by the living roots of GM potato plants, is bound by soil particles and/or rapidly decomposed by the soil microorganisms and, therefore, has no long-lasting effect on key activities of soil microorganisms. Furthermore, our results are in line with Heuer et al. (2002), who showed that compared to natural community shifts, T4 lysozyme was only a minor factor - if any - in changing bacterial community structures of the agroecosystem.

In summary, this model study under laboratory conditions showed that the fingerprint obtained by PyFIMS has potential as a screening technique to analyze changes in rhizodeposition that might have an impact on the composition and activity of rhizosphere or bulk soil microbes. However, relevance of the results for a risk assessment of growing GM crops under field conditions is limited because (1) the relatively small soil volume and high root density differ from field conditions, (2) the rhizodeposition generally can be affected by many biotic and abiotic factors (Jones et al., 2004) other than the release of GM proteins, and (3) baseline studies, i.e. to compare different potato varieties, soils and growth stages are still lacking, so it is impossible to relate the differences found between transgenic and parental lines to the "natural" variation. Despite these limitations, some of which will be overcome in forthcoming studies, the analytical-chemical approach is highly complementary to Catchpole et al. (2005), who recently described a comprehensive comparison of total metabolites in fieldgrown GM and conventional potatoes using a rapid massspectrometric metabolome fingerprinting.

\section{CONCLUSIONS}

Elemental analyses, Py-FIMS, dehydrogenase activity and substrate-induced soil respiration, in agreement with the pertinent literature, showed that we could exclude distinct and direct T4-lysozyme-founded effects of the GM potato plants under study on the rhizodeposition and resulting bulk characteristics of microbial activity in soil.

Among the three methods applied, only Py-FIMS of rhizodeposits proved any, even if so far not well explained, effects of the growth of T4-lysozyme-potato versus nontransgenic potato plants on organic substances leached from soil. Therefore, the Py-FI mass spectrometric fingerprint is to be considered a fast, comprehensive, highly sensitive and reproducible analytical approach to discern any effects GM crops may exert on soil ecological parameters.

Since we observed some, but not well understood, differences in the Py-FI mass spectra of leachates from soil between the non-transgenic parent line and three GM potato lines after a six-week growing period, we will expand this investigation by a refined sampling strategy, which will include exudates collected after each 12 hours of photosynthetic activity and nighttime periods. Furthermore, if differences in the rhizodeposits are detected, potential changes in the associated microflora need to be evaluated, e.g., by molecular fingerprints of $16 \mathrm{~S}$ or 18S rRNA gene fragments amplified from total community DNA (Milling et al., 2004).

\section{MATERIALS AND METHODS}

The experiment was carried out on sandy soil from the Ap horizon of a Cambisol, which had the following analytical characteristics: $\mathrm{pH}$ in $\mathrm{CaCl}_{2}$ 6.6, cation exchange capacity $5.33 \mathrm{cmol}_{\mathrm{c}} \cdot \mathrm{kg}^{-1}$, and elemental composition of $7.9 \mathrm{~g} \cdot \mathrm{kg}^{-1}$ carbon (C), $0.8 \mathrm{~g} \cdot \mathrm{kg}^{-1}$ nitrogen $(\mathrm{N})$ and $1.6 \mathrm{~g} \cdot \mathrm{kg}^{-1}$ sulfur (S). The concentration of plant-available $\mathrm{P}$ (double lactate extract) was $52 \mathrm{mg} \cdot \mathrm{kg}^{-1}$, indicating a medium optimal $\mathrm{P}$ supply. For the experiment about $340 \mathrm{~cm}^{3}$ of non-sterile soil was filled into polycarbonate containers "CombiSart" (Merck, Darmstadt, Germany), in which the plants were grown.

Tubers of the T4-lysozyme potato lines DL10 and DL12 were provided by K. Düring in 1998 (MPB Cologne, Köln, Germany). The one-eyed pieces of potato mini-tubers were exposed for $15 \mathrm{~min}$ in a solution of gibberellic acid ( $\left.1 \mathrm{mg} . \mathrm{L}^{-1}\right)$ and thiourea $\left(6 \mathrm{mg} . \mathrm{L}^{-1}\right)$, and then immediately transferred into the containers of soil. The plants were grown after germination under photoperiod of 12 hours and $20^{\circ} \mathrm{C}$ day/night temperature 


\section{A. Melnitchouck et al.}

for six weeks. The light intensity was $350 \mu \mathrm{mol} \mathrm{m} \mathrm{m}^{-2} \cdot \mathrm{s}^{-1}$. Growing plants were fertilized twice with $50 \mathrm{ml}$ Knop's solution. The experiment included the following variants:

- Control: sandy soil without crops;

- WT: cv. Désirée, non-transgenic potato;

- LH9000: transgenic line expressing the nptII gene (Hausmann and Töpfer, 1999) for the resistance to kanamycin;

- DL10, DL12: independent transgenic lines with similar expression profile carrying the T4 lysozyme coding region fused to the CaMV 35 S promoter and the nptII gene (Düring and Porsch, personal communication).

The experiment was laid out in three replicates. After six weeks (phenological BBCH code 107, Biologische Bundesanstalt für Land- und Forstwirtschaft, 2001) the soil in the containers was leached with distilled water as described by Kuzyakov and Sinyakina (2001), and Melnitchouck et al. (2005). Briefly, the soil containers were completely saturated, and then slowly leached with additional $100 \mathrm{ml}$ of distilled water. Collection of the leachates was completed after 2 hours. In agreement with previous studies we call these leachates rhizodeposits although they also may contain microbial metabolites of rhizodeposits and products of the interaction with soil organic matter, including biomolecules trapped in humic substances. To prevent possible decomposition of organic matter, collected leachates were immediately frozen and freeze-dried. Until analyses, the solid residues were kept in closed vials at $-20{ }^{\circ} \mathrm{C}$. The $\mathrm{C}, \mathrm{N}$ and $\mathrm{S}$ contents were determined by the elemental analyzer Vario EL (Elementar Analysensysteme GmbH, Hanau, Germany).

For Py-FIMS, about $1 \mathrm{mg}$ of freeze-dried leachate sample was transferred to a quartz micro-oven and heated from 110 to $700{ }^{\circ} \mathrm{C}$ in steps of $10 \mathrm{~K}$ in the direct inlet system of a modified double-focusing Finnigan MAT 731 mass spectrometer (Finnigan, MAT, Bremen, Germany). After 19 min of total registration time, about 60 magnetic scans were recorded for the mass range 16 to 1000 Dalton (single spectra). These were combined to obtain one thermogram of total ion intensity (TII) and an averaged mass spectrum. In addition, for each single scan, the ion intensities of marker signals for ten selected classes of chemical compounds in SOM were calculated (Schulten and Leinweber, 1999). All Py-FIMS data were normalized per mg sample. For detailed descriptions of the Py-FIMS methodology and of statistical evaluations of sample weight and residue, volatilized matter, and total ion intensities (TII) see Schulten (1996) and Schulten et al. (1998).
To identify differences between the variants, a principal component analysis (PCA) was carried out with the $11 \mathrm{~m} / \mathrm{z}$ with the largest variance weights, i.e. the ratio of interclass variance of a variable to its intraclass variance (Kowalski and Bender, 1972).

Two weeks after the leaching of rhizodeposits, the plants were cut off, and the bulk soil was used for determinations of (1) substrate-induced soil respiration and (2) dehydrogenase activity. Coarse roots were separated manually from the soil, but fine roots and root hairs remained in the sample and contributed to respiration and enzyme activity. For substrate-induced soil respiration, $20 \mathrm{ml}$ of glucose solution $\left(20\right.$ g.. $\left.\mathrm{L}^{-1}\right)$ were added to each soil sample, and three soil samples of $100 \mathrm{~g}$ from each variant at field capacity were placed for 18 days in an incubation chamber (Auergesellschaft $\mathrm{GmbH}$, Germany). The concentrations of $\mathrm{CO}_{2}$ and $\mathrm{N}_{2} \mathrm{O}$ were determined by IR spectroscopy, and were recorded at intervals of six hours. The dehydrogenase activity was determined as described by Thalmann (1968). This method involves a colorimetric determination of 2,3 , 5-triphenyl formazan (TPF) produced by the reduction of 2, 3, 5-triphenyltetrazolium chloride (TTC) by soil microorganisms. From each variant, $5 \mathrm{~g}$ soil was taken in three replicates. The amount of TPF produced was determined at the wavelength of $546 \mathrm{~nm}$ by an UV-VIS spectrophotometer (Spectrosonic Genesys 5, Milton Roy Company, Rochester, USA).

For all statistical analyses ( $t$-test, ANOVA) the software package STATISTICA 5.0. (StatSoft, Inc., 2002) was used.

\section{ACKNOWLEDGEMENTS}

This study was partly financed by a short-term DAAD NATO grant for postdoctoral scientists (ref. A/03/06778) dedicated to the first author. The authors would like to thank Dr. Yakov Kuzyakov (University of Hohenheim, Stuttgart, Germany) for helpful discussions. Thanks also to three anonymous reviewers who gave helpful suggestions to improve the paper.

Received September 19, 2005; accepted April 28, 2006.

\section{REFERENCES}

Ahrenholz I, Harms K, de Vries J, Wackernagel W (2000) Increased killing of Bacillus subtilis on the hair roots of transgenic T4 lysozyme-producing potatoes. Appl. Environ. Microb. 66: 1862-1865 
Biologische Bundesanstalt für Land- und Forstwirtschaft (2001) Entwicklungsstadien mono- und dikotyler Pflanzen. BBCH Monografie, 2. Auflage, S. 45-50

Brady NC (1990) The nature and properties of soil. Macmillan Publishing Company, New York

Bruinsma M, Kowalchuk GA, van Veen JA (2003) Effects of genetically modified plants on microbial communities and processes in soil. Biol. Fertil. Soils 37: 329-337

Brusetti L, Francia P, Bertolini C, Pagliuca A, Borin S, Sorlini C, Abruzzese A, Sacchi G, Viti C, Giovannetti L, Giuntini E, Bazzicalupo M, Daffonchio D (2004) Bacterial communities associated with the rhizosphere of transgenic $\mathrm{Bt}$ 176 maize (Zea mays) and its non transgenic counterpart. Plant Soil 266: 11-21

Catchpole GS, Beckmann M, Enot, DP, Mondhe M, Zywicki B, Taylor J, Hardy N, Smith A, King RD, Kell DB, Fiehn O, Draper J (2005) Hierarchical metabolomics demonstrates substantial compositional similarity between genetically modified and conventional potato crops. Proc. Natl. Acad. Sci. USA 102: 14458-14462

Cowgill SE, Bardgett RD, Kiezenbrink DT, Atkinson HJ (2002) The effect of transgenic nematode resistance on nontarget organisms in the potato rhizosphere. J. Appl. Ecol. 39: 915-923

De Vries J, Harms K, Broer I, Kriete G, Mahn A, Düring K, Wackernagel W (1999) The acteriolytic activity in transgenic Potato. Syst. Appl. Microbiol. 22: 280-286

Düring K, Mahn A (1999) Freisetzung und Resistenzprüfung transgener Lysozym-Kartoffeln. In: Freisetzungsbegleitende Sicherheitsforschung mit gentechnisch veränderten Pflanzen und Mikroorganismen (Schiemann J, Hrg). Proceedings zum BMBF-Workshop, BBA Braunschweig, 25-26 Mai 1998. BEO (Projektträger Biologie, Energie, Umwelt des BMBF), Jülich. S. 39-44

Gransee A, Wittenmayer L (2000) Qualitative and quantitative analysis of water-soluble root exudates in relation to plant species and development. J. Plant Nutr. Soil Sci. 163: 381-385

Hausmann L, Töpfer R (1999) Entwicklung von PlasmidVektoren. In Brauer D, Röbbelen G, Töpfer R, eds, BioEngineering für Rapssorten nach Maß, Vorträge für Pflanzenzüchtung 45, 153-171

Heuer H, Kroppenstedt RM, Lottmann J, Berg G, Smalla K (2002) Effects of T4 lysozyme release from transgenic potato roots on bacterial rhizosphere communities are negligible relative to natural factors. Appl. Environ. Microb. 68: 13251335

Hütsch BW, Augustin J, Merbach W (2002) Plant rhizodeposition - an important source for carbon turnover in soils. J. Plant Nutr. Soil Sci. 165: 397-407

Jones DL, Hodge A, Kuzyakov Y (2004) Plant and mycorrhizal regulation of rhizodeposition. New Phytol. 163: 459-480

Kjøller R, Rosendahl S (2000) Effect of fungicides on arbuscular mycorrhizal fungi: different responses in alkaline phosphatase activity of external and internal hyphae. Biol. Fertil. Soils 31: 361-365

Kowalski BR, Bender CF (1972) Pattern recognition. A powerful approach to interpreting chemical data. J. Am. Chem. Soc. 94: 5632-5639

Kuzyakov Y, Sinyakina S (2001) A novel method for separating root-derived organic compounds from root respiration in non-sterilized soils. J. Plant Nutr. Soil Sci. 164: 511-517

Kuzyakov Y, Leinweber P, Sapronov D, Eckhardt K-U (2003) Quantitative assessment of root exudates in non-sterile soil by analytical pyrolysis. J. Plant Nutr. Soil Sci. 166: 719723

Leinweber P, Schulten H-R, Kalbitz K, Meißner R, Janke H (2001) Fulvic acid composition in degraded fenlands. J. Plant Nutr. Soil Sci. 164: 371-379

Lottmann J, Heuer H, Smalla K, Berg G (1999) Influence of transgenic T4-lysozyme-producing potato plants on potentially beneficial plant associated bacteria. FEMS Microbiol. Ecol. 29: 365-377

Melnitchouck A, Leinweber P, Eckhardt K-U, Beese R (2005) Qualitative differences between day- and nighttime rhizodeposition in maize (Zea mays L.) as investigated by pyrolysis-field ionization mass spectrometry. Soil Biol. Biochem. 37: 155-162

Milling A, Smalla K, Maidl FX, Schloter M, Munch JC (2004) Effects of transgenic potatoes with an altered starch composition on the diversity of soil and rhizosphere bacteria and fungi. Plant Soil 266: 23-39

Paul EA, Clark FE (1996) Soil Microbiology and Biochemistry, 2nd ed, Academic Press, San Diego

Protein Data Bank (2003) http://www.rcsb.org/pdb/cgi/ explore.cgi?job=download;pdbId=256L;page $=\& o p t=$ show $\&$ format $=$ mmCIF\&pre $=1$ (accessed March 26, 2003)

Rausch C, Daram P, Brunner S, Jansa J, Lalol M, Leggewie G, Amrhein N, Bucher M (2001) A phosphate transporter expressed in arbuscule-containing cells in potato. Nature $\mathbf{4 1 4}$ : 462-466

Schulten H-R (1996) Direct Pyrolysis-Mass Spectrometry of Soils: A Novel Tool in Agriculture, Ecology, Forestry and Soil Science. In Yamasaki S, Boutton TW, eds, Mass spectrometry of soils, Marcel Dekker, New York, pp 373-436 Schulten H-R, Leinweber P (1999) Thermal stability and composition of mineral-bound organic matter in density fractions of soil. Eur. J. Soil Sci. 50: 237-248

Schulten H-R, Leinweber P, Jandl G (2002) Analytical pyrolysis of humic substances and dissolved organic matter in water. In Frimmel FH, Abbt-Braun G, Heumann K-G, Hock B, Lüdemann H-D, Spiteller M, eds, Refractory Organic Substances in the Environment, Wiley-VCH, Weinheim, pp 163-187

Schulten H-R, Leinweber P, Schnitzer M (1998) Analytical Pyrolysis and Computer Modelling of Humic and Soil Particles. In Structure and Surface Reactions of Soil Particles, John Wiley \& Sons, pp 281-324 


\section{A. Melnitchouck et al.}

Sessitsch A, Gyamfi S, Tscherko D, Gerzabek MH, Kandeler E (2004) Activity of microorganisms in the rhizosphere of herbicide treated and untreated transgenic glufosinate-tolerant and wildtype oilseed rape grown in containment. Plant Soil 266: 105-116

Simek M, Hopkins DW, Kalcik J, Picek T, Santruckova H, Stana J, Travnik K (1999) Biological and chemical properties of arable soils affected by long-term organic and inorganic fertilizer applications. Biol. Fertil. Soils 29: 300-308

Sorge C, Schnitzer M, Schulten H-R (1993) In-source pyrolysis-field ionization mass spectrometry and Curie-point gas chromatography/mass spectrometry of amino acids in humic substances and soils. Biol. Fertil. Soils 16: 100-110

StatSoft, Inc. (2002) Electronic Statistics Textbook. Tulsa, OK: StatSoft. http://www.statsoft.com/textbook/stathome.html (accessed August 5, 2002)
Tabatabai MA (1994) Soil enzymes. In Weaver RW, Angle S, Bottomley P, Bezdicek D, Smith S, Tabatabai MA, Wollum A, eds, Methods of Soil Analysis. Part 2. Microbiological and Biochemical Properties, Soil Science Society of America, Madison/WI

Thalmann A (1968) Zur Methodik der Bestimmung der Dehydrogenaseaktivität im Boden mittels Triphenyltetrazoliumchlorid (TTC), Landwirtsch. Forsch. 21: 249258

Verhoef HA, van Gestel CAM (1995) Methods to Assess the Effects of Chemicals on Soils. In Linthurst RA, Bourdeau P, Tardiff RG, eds, Methods to Assess the Effects of Chemicals On Ecosystems, John Wiley \& Sons, Chichester, pp 223 257

Wood M (1995) Environmental Soil Biology, Blackie Academic and Professional, Glasgow, London

To access this journal online: www.edpsciences.org 